\title{
Structural Assessment and EDS Analysis of Uruguayan Wood Impregnated With Zinc Borate (ZnB)
}

Álvaro A. Camargo ${ }^{1 *}$, Alejandro Marquéz ${ }^{2}$, Diego N. Passarella ${ }^{1}$, Laidy E. Hernandez-Mena ${ }^{1}$, Ana Laura Reyes ${ }^{2}$, Claudia M. Ibáñez ${ }^{3}$

${ }^{1 .}$ Procesos Industriales de la Madera, Sede Tacuarembó, Universidad de la República, Tacuarembó, Uruguay.

2. Unidad de Microscopia Electrónica de Barrido, Facultad de Ciencias, Universidad de la República, Montevideo, Uruguay.

3. Instituto Superior de Estudios Forestales, Sede Tacuarembó, Universidad de la República, Tacuarembó, Uruguay.

* Corresponding author: alvaro.camargo@,cut.edu.uy

Ammoniacal solution of zinc borate $(\mathrm{ZnB})$ can present fire retardant and protection against microorganisms properties once it is applied to wood [1]. Recent studies have evaluated the behavior against fire of Eucalyptus grandis samples grown at the north region of Uruguay, showing a lower burning rate when it is impregnated with $\mathrm{ZnB}$ [2]. On top of that, the morphology of the surfaces exposed to flames present high degree of deformed fibers when the sample was not treated in the solution. Presence of $\mathrm{ZnB}$ is found on the surface of the treated and then burned samples [2].

This study evaluates the morphological differences between samples of Pinus taeda and Eucalyptus grandis subjected to burning resistance tests. Samples with and without ZnB impregnation process were compared using Scanning Electron Microscopy (SEM) and X-ray Energy Dispersion Spectroscopy (EDS). Weight and atomic ratios of $\mathrm{Zn}$ against the rest of inorganic elements, for burned and solely treated samples, were obtained using EDS [3].

It was observed that the surface of treated wood (figure 1b) is prone to milder structural damage than untreated wood (figure 1a), this is revealed by the sustained orientation of fibers and the absence of cracks, that are presented on burned samples of untreated samples. The EDS analysis reveals a higher concentration of $\mathrm{Zn}$ on the surface of E.grandis after burning tests (table 1), while the distribution of $\mathrm{Zn}$ after flame exposure is more homogeneous on P.taeda samples (figure 1c).

Based on these results, we conclude that $\mathrm{ZnB}$ treatment has a positive effect on the fire response of the woods studied. Part of the research has been funded by the CSIC (Comisión Sectorial de Investigación Científica) of UdelaR (Universidad de la República, Uruguay) [4]. 
References

[1] E. Altuntas, N. Narlioglu, M.H. Alma, BioResources. 12(4) (2017), p. 6971.

[2] A. Camargo, C.M. Ibáñez, MRS Adv. 3(61) (2018), p. 3551.

[3] N. Ayrilmis et al., Constr. Build. Mater. 33 (2012), p. 63.

[4] The authors acknowledge support for research from the CSIC of UdelaR.
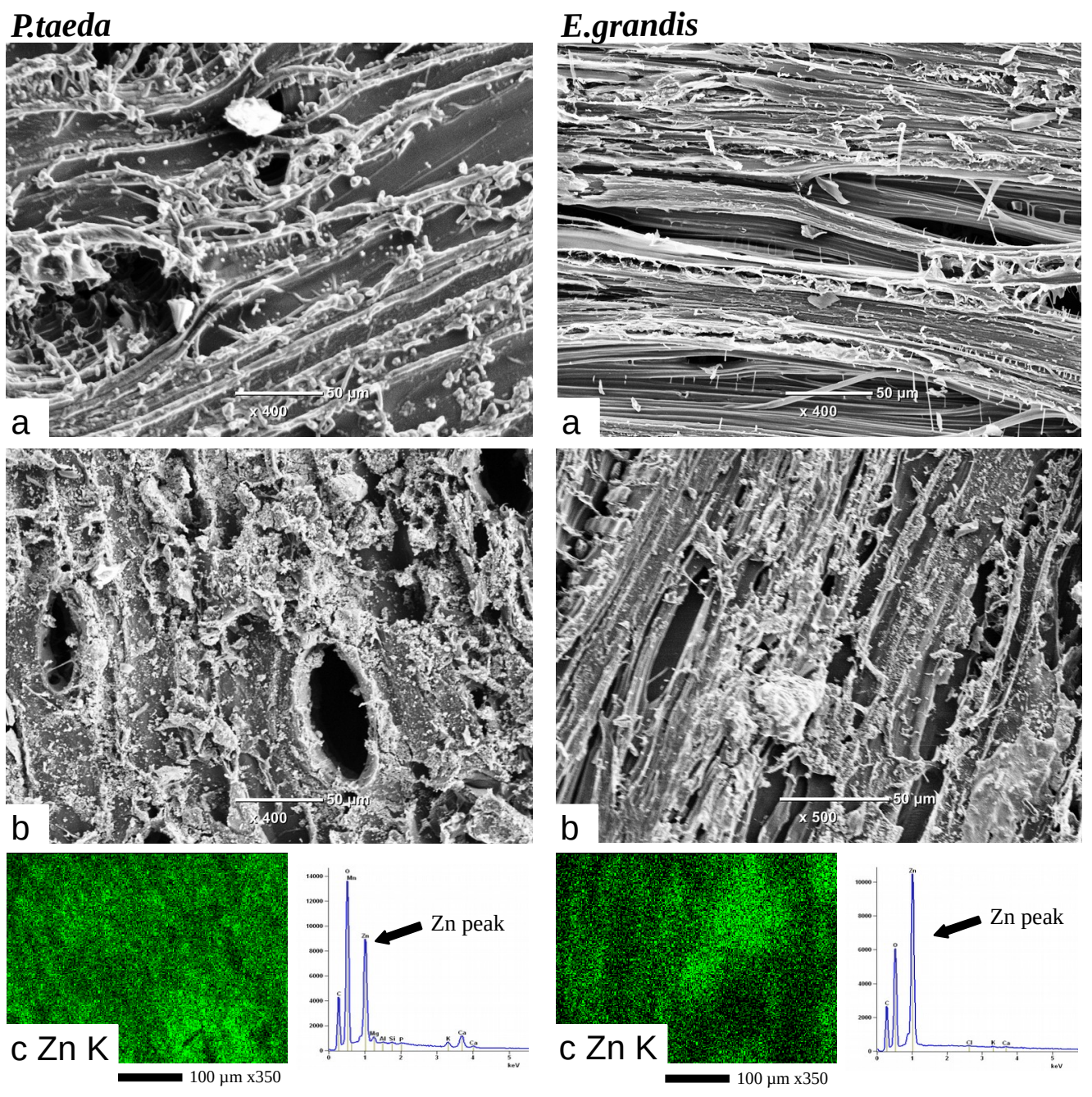

Figure 1. SEM images of tangential slices of P.taeda and E.grandis: (a) untreated wood after fire exposure, (b) ZnB treated wood after fire exposure, (c) Zn mapping of pictures depicted in (b) and EDS spectra.

\begin{tabular}{lcccc}
\hline [Zn] & \multicolumn{2}{c}{ P.taeda } & \multicolumn{2}{c}{ E.grandis } \\
& \% weight \pm SD & \% atomic \pm SD & \% weight \pm SD & \% atomic \pm SD \\
\hline a & 0 & 0 & 0 & 0 \\
b & $70.37 \pm 0.16$ & $55.09 \pm 0.076$ & $95.70 \pm 0.29$ & $82.12 \pm 0.10$ \\
Initial* $^{*}$ & $80.20 \pm 0.07$ & $64.23 \pm 0.04$ & $93.90 \pm 0.40$ & $88.62 \pm 0.14$ \\
\hline
\end{tabular}

Table 1. Zn concentration obtained with EDS: (a) untreated wood after fire exposure, (b) ZnB treated wood after fire exposure, and (Initial*) Zn ratio in impregnated wood without exposure to flame. 